\title{
Preparation of Bifidobacterium breve encapsulated in low methoxyl pectin beads and its effects on yogurt quality
}

\author{
Mengyang Li, ${ }^{1,2}$ Yunxiang Jin, ${ }^{1,2}$ Yawei Wang, ${ }^{1,3}$ Li Meng, ${ }^{1,3}$ Na Zhang, ${ }^{4}$ Ying Sun, ${ }^{5}$ Jingfei Hao, ${ }^{1,2}$ Qi Fu, ${ }^{1,2}$ \\ and Qingshen Sun ${ }^{1,3 *}$ \\ ${ }^{1}$ Engineering Research Center of Agricultural Microbiology Technology, Ministry of Education, Heilongjiang University, Harbin 150500, China \\ ${ }^{2}$ Key Laboratory of Molecular Biology, College of Heilongjiang Province, School of Life Sciences, Heilongjiang University, Harbin 150080, China \\ ${ }^{3}$ Key Laboratory of Microbiology, College of Heilongjiang Province, School of Life Sciences, Heilongjiang University, Harbin 150080, China \\ ${ }^{4}$ College of Food Engineering, Harbin University of Commerce, No. 138 TongDa Street Daoli District, Harbin 150076, China \\ ${ }^{5}$ College of Tourism and Cuisine, Harbin University of Commerce, No. 138 TongDa Street Daoli District, Harbin 150076, China
}

\section{ABSTRACT}

Yogurt is a popular product worldwide partly because of the health-promoting effects of the probiotics that it contains. Probiotics with high survivability constitute a promising direction for fortified yogurt products. This study aimed to prepare Bifidobacterium breveloaded yogurt with the bacteria surviving transit to the lower part of small intestine or colon. Bifidobacterium breve beads were prepared through an ion-crosslinking method using low methoxyl pectin as the encapsulating material. Features such as encapsulation efficiency and stability during storage and passage through the simulated gastrointestinal tract were studied in vitro. A commercial starter was used for yogurt fermentation, and $B$. breve with or without encapsulation was added as a probiotic supplement with the starter or 3 to $4 \mathrm{~h}$ after fermentation. The effects of $B$. breve beads on yogurt characteristics were evaluated after different fermentation processes: BC, milk fermented with marketed yogurt starter; UBFF, unencapsulated $B$. breve added to fresh milk and then fermented; EBFF, encapsulated $B$. breve added to fresh milk and then fermented; UBAF, unencapsulated $B$. breve added after fermentation with the starter; and EBAF, encapsulated $B$. breve beads added 3 to $4 \mathrm{~h}$ after fermentation with the starter. Evaluation was based on texture, electronic nose, and electronic tongue analyses. The particle size analysis of $B$. breve beads showed that they were uniform, mostly spherical, 1 to $1.5 \mathrm{~mm}$ in diameter with encapsulating efficiency higher than 99\%. Following treatment with the simulated gastrointestinal tract conditions, the number of $B$. breve decreased by 1.76 and $4.82 \mathrm{log} \mathrm{cfu} / \mathrm{g}$ for $B$. breve beads and unencapsu-

\footnotetext{
Received August 24, 2018.

Accepted February 18, 2019.

*Corresponding author: kejiansqs@163.com or sunqingshen@hlju .edu.cn
}

lated $B$. breve, respectively. The EBAF group showed the lowest viscosity $(2,235.67 \mathrm{cP})$ at $\mathrm{d} 0$, and the lower postfermentation degree was reflected by the slow increase in yogurt viscosity. All groups kept a relatively stable $\mathrm{pH}$ during storage. The cohesiveness values of the EBAF and UBAF groups were significantly higher than those of the other groups. The trends in texture changes within the $\mathrm{BC}, \mathrm{UBFF}$, and $\mathrm{EBFF}$ groups were similar, and the UBAF and EBAF groups showed similar trends. In conclusion, B. breve beads showed good stability in vitro and improved yogurt characteristics by increasing the survival rate of the encapsulated cells. Good compatibility of low methoxyl pectin beads with yogurt was also observed.

Key words: Bifidobacterium breve, low methoxyl pectin, beads, yogurt fermentation

\section{INTRODUCTION}

Functional foods containing probiotics have undergone rapid growth in the field of fortified foods (Champagne et al., 2018). The term probiotic can only be used for products that deliver a suitable amount of well-defined, living microorganisms that benefit the well-being of the host. Live cultures include probiotic and non-probiotic organisms. The former includes probiotic drugs, probiotic medical foods, probiotic foods, and non-oral probiotics, among others, whereas nonprobiotic cultures include fermented foods with an undefined microbial content (Hill et al., 2014). These active microorganisms are present in the host gut and have beneficial effects, such as maintaining the intestinal microbial balance, inhibiting pathogen invasion, and reducing intestinal permeability. Based on the important physiological functions of probiotics, probiotics-based products are becoming increasing common (Ranadheera et al., 2010; Aryana and Olson, 2017; Sarao and Arora, 2017; Champagne et al., 2018). Probiotics that reach the gastrointestinal (GI) tract may be helpful for the production of short-chain fatty acids (Sarao and Arora, 2017), 
but to have health-promoting effects, the concentration of viable cells should be at least $10^{7} \mathrm{cfu} / \mathrm{mL}$ (Chavarri et al., 2010). Attaining this number can be difficult due to conditions during production, transportation, and preservation processes and exposure to gastric juice and bile during transit through the GI tract. Therefore, effective measures are needed to increase the vitality of probiotics, and encapsulation of the bacteria shows great promise in this regard. Probiotics can be encapsulated in materials such as polysaccharides, proteins, and lipids, among others, for protection against the above-mentioned harsh conditions. Pectin, a member of the polysaccharide family, exists widely in natural foods and is commonly used as a food additive. Low methoxyl pectin (LMP) can be cross-linked with $\mathrm{Ca}^{2+}$ to form microparticles or nanoparticles, and it is widely used as a carrier to deliver drugs to the colon (Bourgeois et al., 2006; Nguyen et al., 2014; Ghibaudo et al., 2018). In the current study, we prepared LMP beads to encapsulate $B$. breve. We then evaluated the performance of the beads in terms of encapsulation efficiency and performance in simulated GI and storage stability tests.

Yogurt is a good vehicle for carrying probiotics to the human intestinal tract, not only because it is a popular food, but also it typically has a high concentration of probiotics (Yang and Sheu, 2012; Champagne et al., 2018). Over the past 100 years, yogurt has undergone improvements and new developments, and it is the leading cultured dairy product in the United States (Aryana and Olson, 2017). Several strategies have been used to improve the functions of yogurt with probiotics (Champagne et al., 2018); for example, yogurt supplemented with Lactobacillus paracasei N1115 can be used to protect elderly people against respiratory infections (Pu et al., 2017).

During fermentation, the yogurt $\mathrm{pH}$ decreases, which is detrimental to many microorganisms. In addition, when consumed, the yogurt passes through the GI tract, where extreme $\mathrm{pH}$ and bile salt may destroy probiotics (Champagne et al., 2018). Therefore, in this study, B. breve beads were first prepared using LMP to protect the bacteria. We then evaluated the effects of $B$. breve beads on yogurt features, including $\mathrm{pH}$, acidity, and viscosity during storage. We also used electronic nose and tongue equipment to analyze odor and flavor characteristics of the yogurt.

\section{MATERIALS AND METHODS}

\section{Materials}

Bifidobacterium breve (strain no. CICC 6182) was purchased from the Institute of Microbiology, Chinese
Academy of Sciences (Beijing, China); LMP was purchased from Anhui Yu Ning Biotechnology Co. Ltd. (Suzhou, China); anhydrous calcium chloride was purchased from Zhejiang Juhua Xinlian Chemical Co. Ltd. (Quzhou, China); and anaerobic tank AG035 and gas production anaerobic bag C3500 were purchased from Mitsubishi (Tokyo, Japan).

\section{Strain Activation and Culture}

Bifidobacterium breve powder was dispensed into 0.5 $\mathrm{mL}$ of sterilized TPY liquid medium. The bacterial dispersion was transferred onto TPY solid culture medium and cultured anaerobically for $48 \mathrm{~h}$ at $37^{\circ} \mathrm{C}$. A single colony was then transferred to de Man, Rogosa, and Sharpe (MRS) liquid culture medium supplemented with L-cysteine monohydrochloride $(5 \mathrm{mg} / 100 \mathrm{~mL})$ and incubated at $37^{\circ} \mathrm{C}$ for $24 \mathrm{~h}$ anaerobically.

\section{Preparation of B. breve Beads}

The $100-\mathrm{mL}$ bulk cultures of $B$. breve were centrifuged at $1,684 \times g$ for $15 \mathrm{~min}$, and the pellets were then resuspended in $5 \mathrm{~mL}$ of sterile saline. The LMP beads were prepared as previously reported (Aydin and Akbuga, 1996; Sandoval-Castilla et al., 2010; Oehme et al., 2011; Sandolo et al., 2011; Nguyen et al., 2014; Ghibaudo et al., 2018). In brief, $5 \mathrm{~mL}$ of $2 \%$ LMP solution (wt/vol) was prepared by dissolving $0.1 \mathrm{~g}$ of LMP into $4.9 \mathrm{~mL}$ of distilled $\mathrm{H}_{2} \mathrm{O}$. The solution was then mixed with the concentrated bacterial suspension, using a vortex mixer. The mixture was transferred into a beaker containing $300 \mathrm{~mL}$ of a $\mathrm{CaCl}_{2}$ solution $(300$ $\mathrm{mmol} / \mathrm{L}$ ) using a syringe with a no. 7 needle, with stirring on a magnetic stirrer. The prepared beads were filtered through gauze and thoroughly washed with sterile water. Finally, the cleaned beads were mixed well with cryoprotectant and lyophilized.

\section{Encapsulation Efficiency Determination}

The encapsulation efficiency was determined as previously described (Sandoval-Castilla et al., 2010; Vaziri et al., 2018), with some modifications. Briefly, the collected bulk cultures of $B$. breve were subjected to serial dilution and enumerated by the plate colony count, which was recorded as the primary number of bacteria $(A)$. Wet beads $(0.1 \mathrm{~g})$ as prepared above were treated with $30 \mathrm{~mL}$ of EDTA (50 mmol/L, pH 8.0) under agitation for complete disintegration, and the cell pellets were collected by centrifugation at $1,684 \times g$ for 15 min and washed twice with sterilized saline. The pellets were then diluted for plate counting, and the number of cells $(B)$ was calculated. The encapsulation efficiency 
(EE) was calculated according to Equation [1]: EE (\%) $=(B / A) \times 100 \%$.

\section{Simulation of GI Conditions}

The in vitro simulated GI tests were conducted as previously reported (Tomaro-Duchesneau et al., 2012), with some modifications. In brief, $1 \mathrm{~mL}$ of $B$. breve suspension (containing $10.45 \mathrm{log}$ cfu $B$. breve) or $0.1 \mathrm{~g}$ of $B$. breve beads (containing $10.38 \mathrm{log}$ cfu $B$. breve) was subjected to treatment with $30 \mathrm{~mL}$ of simulated gastric fluid (SGF, $0.03 \mathrm{M} \mathrm{NaCl}$ solution containing $1.6 \mathrm{~g}$ of pepsin in $500 \mathrm{~mL}$ of water, $\mathrm{pH} 2.0$ ), with shaking at $180 \mathrm{rpm}$ for $2 \mathrm{~h}$. Afterward, the pellets were collected by centrifugation at $1,684 \times g$ for $15 \mathrm{~min}$, and the collected cells were divided. One half was used for plate counting as above, while the other half was placed in 30 $\mathrm{mL}$ of simulated bile juice (SBF), which was prepared by adding $1 \mathrm{~g}$ of porcine bile extract to $100 \mathrm{~mL}$ of 0.2 $M$ phosphate buffer solution ( $\mathrm{pH} 7.4$ ), with shaking at $180 \mathrm{rpm}$ for $20 \mathrm{~min}$. The mixture was centrifuged for 15 min at $1,684 \times g$ after SBJ treatment, and viable cells were counted. The pellets were then placed in $30 \mathrm{~mL}$ of simulated intestinal fluid (SIF), which was prepared by dissolving $2 \mathrm{~g}$ of pancreatin in $400 \mathrm{~mL}$ of $0.2 \mathrm{MPBS}$ (pH 7.4). After $180 \mathrm{rpm}$ shaking for $2 \mathrm{~h}$, the viable cells were counted.

\section{Stability Test}

Vacuum freeze-dried $B$. breve beads were placed at $-20^{\circ} \mathrm{C}, 4^{\circ} \mathrm{C}$, and ambient temperature $\left(20 \pm 2^{\circ} \mathrm{C}\right)$ conditions, respectively, for $13 \mathrm{wk}$. Each week, $0.1 \mathrm{~g}$ of beads under each temperature condition were removed and placed in $30 \mathrm{~mL}$ of EDTA solution $(50 \mathrm{mmol} / \mathrm{L}$, $\mathrm{pH}$ 8.0) and stirred at $180 \mathrm{rpm}$ at $37^{\circ} \mathrm{C}$ until completely disintegrated. The resultant solution was then serially diluted and plated for counting. The freeze-dried unencapsulated $B$. breve powder treated under the same conditions was used as control. The cell survival rate was calculated as the percentage of colonies after a certain period of storage based on the number before storage.

\section{Yogurt Fermentation}

Fresh milk (Yili, Hohhot, Inner Mongolia, China) was purchased from a local supermarket. The yogurt was produced as previously described (Adhikari et al., 2000; Yang and Sheu, 2012; Caleja et al., 2016). Briefly, the fresh milk was heated at $85^{\circ} \mathrm{C}$ for $15 \mathrm{~min}$. Food-grade $\mathrm{CaCl}_{2}$ was added to the milk at $0.04 \%$ (wt/wt), and $0.5 \%$ corn starch (wt/wt) was dissolved in hot water and added to the milk. After being mixed, the solution was cooled to 37 to $45^{\circ} \mathrm{C}$. Next, a commercial yogurt starter was activated and added to the milk at a ratio of $1 \mathrm{~g}$ of starter to $500 \mathrm{~mL}$ of milk. Then, the milk was poured into autoclaved bottles and fermented at 42 to $45^{\circ} \mathrm{C}$ for 6 to $8 \mathrm{~h}$.

Five types of yogurt were produced: blank control with milk fermented with commercial yogurt starter (BC); unencapsulated B. breve added along with the yogurt starter to fresh milk and then fermented (UBFF); encapsulated B. breve added together with the yogurt starter to fresh milk and then fermented (EBFF); unencapsulated B. breve added 3 to $4 \mathrm{~h}$ after yogurt fermentation with the commercial starter (UBAF); and encapsulated $B$. breve beads added 3 to $4 \mathrm{~h}$ after yogurt fermentation with the commercial starter (EBAF).

The $B$. breve with or without encapsulation was added to the milk at a concentration of $7.5 \mathrm{log} \mathrm{cfu} / \mathrm{g}$ milk at the same time as the starter or 3 to $4 \mathrm{~h}$ after fermentation. Figure 1 shows the flowchart for preparation of yogurt containing the $B$. breve beads. All yogurts were stored at $4^{\circ} \mathrm{C}$, and characteristics were tested at $0,1,3,5$, and $7 \mathrm{~d}$ after fermentation. The $\mathrm{pH}$ of the samples was measured using a $\mathrm{pH}$ meter, and pictures were taken of all products.

\section{Yogurt Characterization}

Acidity. The acidity of the yogurt was determined by acid-base titration. Ten milliliters of yogurt was transferred into 150-mL Erlenmeyer flasks, and then mixed with $20 \mathrm{~mL}$ of distilled water containing 2 drops of phenolphthalein indicator. The mixture was then titrated with sodium hydroxide standard solution, and the volume of the titration solution consumed $(V)$ was recorded. The acidity values of the sample are expressed in degrees Theurer $\left({ }^{\circ} \mathrm{T}\right)$ as follows: ${ }^{\circ} \mathrm{T}=V \times 10$.

Viscosity. The viscosity of the samples was determined at $20^{\circ} \mathrm{C}$ using a Brookfield DV-II Viscometer (Ametek Brookfield, Middleborough, MA) with no. 64 rotor at $1.0 \mathrm{rpm}$ and 20 to $80 \%$ torque.

Texture Determination. Yogurts were analyzed for hardness and cohesiveness using a TA-XT Express physical property tester with $\mathrm{P} / 36 \mathrm{R}$ probe (Stable Micro Systems, Surrey, UK) as previously reported (Curti et al., 2017). Textural properties were analyzed by performing 2 sequential compression tests with a cylindrical-shaped probe (25-mm diameter) separated by a rest phase of $30 \mathrm{~s}$. Each sample was pressed up to $70 \%$ of its original length. The test distance was 15.0 $\mathrm{mm}$. The probe speeds before, during, and after test were $5.0,2.5$, and $2.0 \mathrm{~mm} / \mathrm{s}$, respectively. The measure- 
ment time was $5.00 \mathrm{~s}$, and the induction force was 5.0 $\times g$.

Bifidobacterium breve Activity. The number of original bacteria in yogurt was determined by plate counting as done previously. The simulated GI test for all the samples during $7 \mathrm{~d}$ storage was conducted as above.

Sample Discrimination. After fermentation, the yogurt samples were placed at $4^{\circ} \mathrm{C}$ for $3 \mathrm{~d}$ and then underwent electronic nose and electronic tongue analysis.

Electronic Nose Analysis. The electronic nose analysis followed a previously reported procedure (Zhao et al., 2018). Before the experiment, the prepared yogurt samples were pipetted into $50-\mathrm{mL}$ clean glass bottles with disposable $10-\mathrm{mL}$ syringes and left to equilibrate for $30 \mathrm{~min}$ at $25^{\circ} \mathrm{C}$ to develop headspace for detection. Conditions for electronic nose (iNose system, Isenso, New York, NY) use were as follows: sample preparation time for $5 \mathrm{~s}$, detection time for $60 \mathrm{~s}$, measurement count for $1 \mathrm{~s}$, automatic zero adjustment time for $10 \mathrm{~s}$, cleaning time for $240 \mathrm{~s}$, internal flow at $400 \mathrm{~mL} / \mathrm{min}$, and injection flow rate at $400 \mathrm{~mL} / \mathrm{min}$. Each sample was measured once, and the average value of triplicate samples was used in principal component analysis and discriminant function analysis.

Electronic Tongue Analysis. Thirty-milliliter samples from each group were mixed with $60 \mathrm{~mL}$ of sterile water and centrifuged at $3,790 \times g$ for $10 \mathrm{~min}$ at $20^{\circ} \mathrm{C}$. The supernatant was vacuum filtered, and the filtrate was directly poured into a special container for the electronic tongue analysis ( $25 \mathrm{~mL}$ per sample). The SmarTongue system (Isenso) was used in this experiment, and the primary parts of the system included a sensor array, signal excitation acquisition system, and multivariate mathematical statistics system. The detection probe was composed of a specific multichannel cross-sensitive sensor array. The working electrodes included a gold electrode, palladium electrode, silver electrode, platinum electrode, titanium electrode, and tungsten electrode. The auxiliary electrode was a platinum electrode with a diameter of $2 \mathrm{~mm}$, and a silver/ silver chloride electrode was used as the reference electrode. Distilled water was used as the cleaning solvent. The sampling time was $180 \mathrm{~s}$, once per second $(\mathrm{n}=5)$. Finally, 3 stable test data were selected for principal component analysis and discriminant function analysis.

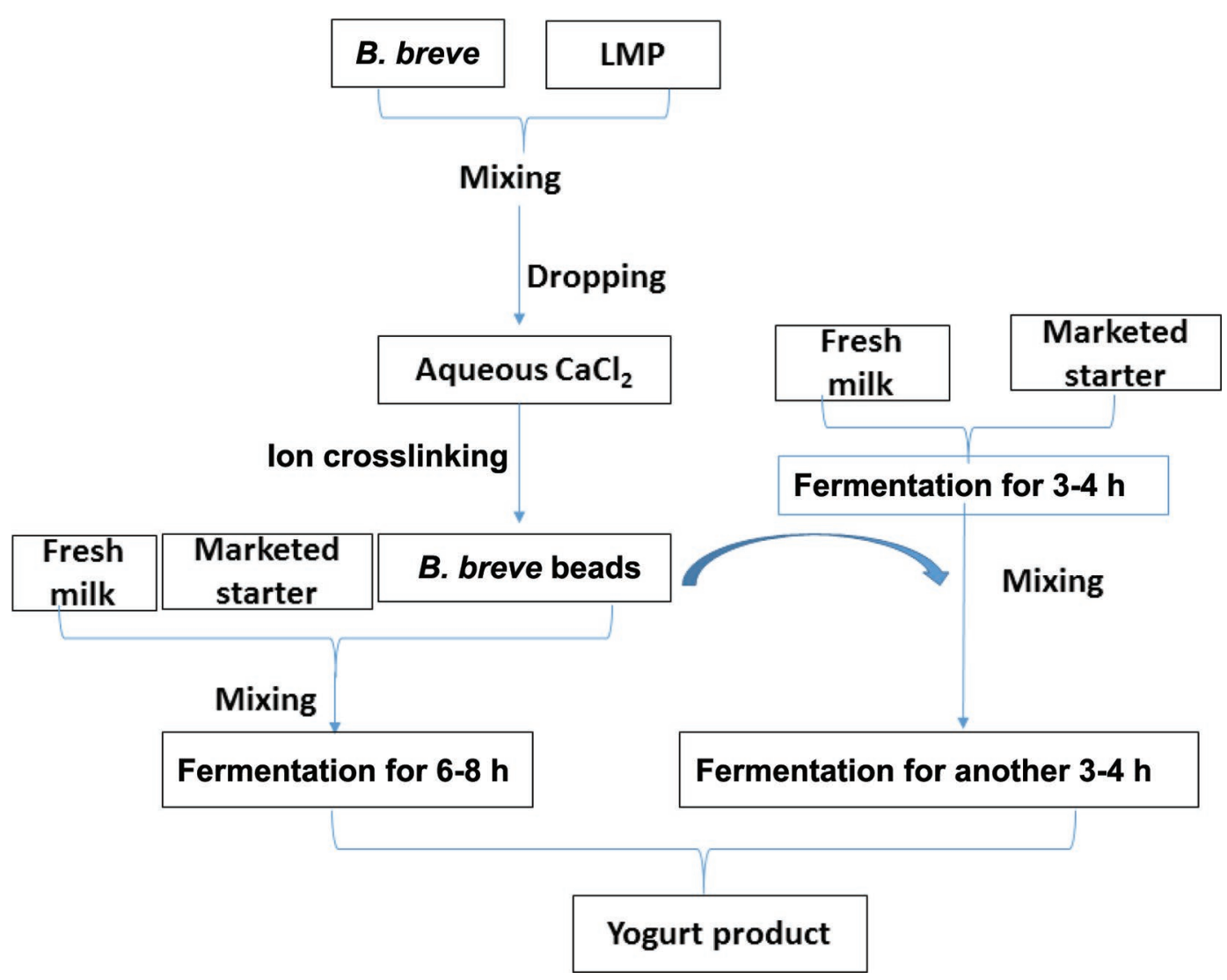

Figure 1. Schematic diagram of the preparation of yogurt containing Bifidobacterium breve beads. LMP $=$ low methoxyl pectin. 


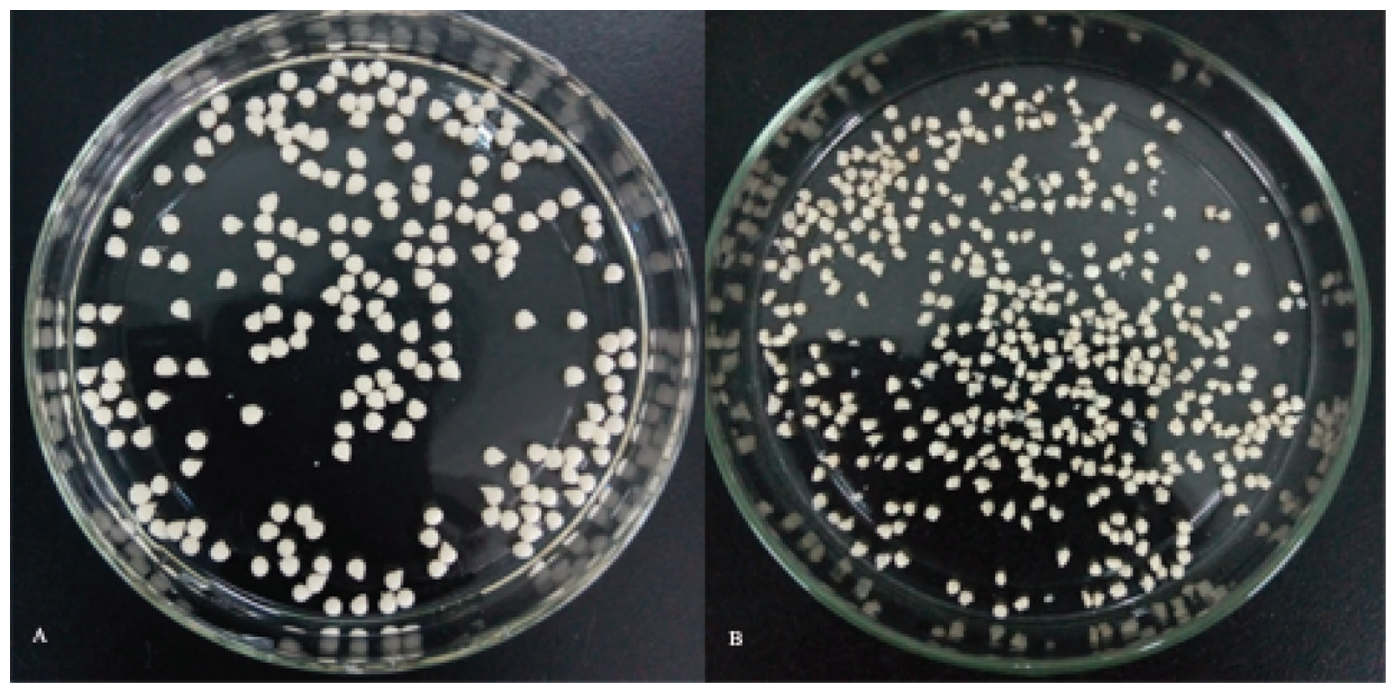

Figure 2. Morphology of Bifidobacterium breve beads before (A) and after (B) freeze drying.

\section{Statistical Analysis}

At least 3 samples were used for each analysis. The Origin 8.0 software(OriginLab, Northampton, MA) was used for data analysis, and the data are expressed as mean \pm standard deviation (SD). The statistical significance was analyzed by 1 -way ANOVA at $P<0.05$ level.

\section{RESULTS AND DISCUSSION}

Probiotics and their derived products show great promise in improving human health (Saldanha, 2008; Champagne, 2012; Vieira da Silva et al., 2016; Champagne et al., 2018). A pivotal question is how to ensure the survival of probiotics under different environmental conditions, such as temperature, water content, and transport in vitro and exposure to gastric acid and bile juice in vivo (Champagne, 2012; Cook et al., 2012; Khosravi Zanjani et al., 2014; Sarao and Arora, 2017). Another challenge involves how to protect the activity of probiotics in popular foods, such as yogurt and other fermented products (Ranadheera et al., 2012; Yang and Sheu, 2012; Pu et al., 2017). To address these issues, we developed a process for loading $B$. breve into pectin beads and then characterized the in vitro stability. We also studied the use of these beads in yogurt fermentation.

\section{Characterization of the Pectin Beads Loaded with $B$. breve}

Figure 2 shows that the beads prepared in this study were white, uniform in particle size distribution (1-1.5 $\mathrm{mm}$ in diameter), spherical, and smooth, with good fluidity. No cross-linking among particles was present after lyophilization, and the encapsulation efficiency was higher than $99 \%$. This excellent encapsulation efficiency was significantly higher than reported previously (Rodklongtan et al., 2014).

The rationale for using LMP to encapsulate $B$. breve in this study was based on several points. First, it is plant derived, with no toxicity (Vincent and Williams, 2009), and it has been widely used as a delivery vector for colon-targeted medications (Liu et al., 2006; Bigucci et al., 2008; Das et al., 2011; Jung et al., 2013). In addition, the beads can be easily prepared by a simple ion-crosslinking process (Liu et al., 2006; de Souza et al., 2009; Jung et al., 2013; Ribeiro et al., 2014; Belscak-Cvitanovic et al., 2015). These points collectively indicated that LMP could also be used as carrier for probiotics delivery.

\section{Simulated Gastrointestinal Test}

As shown in Table 1, unencapsulated B. breve showed a decrease of $4.82 \mathrm{log} \mathrm{cfu} / \mathrm{g}$ after treatment with simulated gastric juice, bile, and intestinal juice, while the $B$. breve in beads decreased by only $1.76 \mathrm{log} \mathrm{cfu} / \mathrm{g}$ after the same treatment. The gastric juice showed the largest destructive effects for unencapsulated $B$. breve, with more than $4 \log$ cfu loss after treatment in SGF for 2 $\mathrm{h}$, while less than 1 log cfu was lost when the bacteria were encapsulated in LMP beads. This experiment revealed that $B$. breve counts declined rapidly in the gastric environment, similar to other probiotics (Rodklongtan et al., 2014), and LMP beads could protect $B$. breve effectively. 
The stability of probiotics during storage and in vivo digestion is very important because the number of viable cells reaching the colon determines whether these probiotics are able to exert a healthful effect. The effect arises not only because of the enrichment of various flora in the colon, but also because of the interactive effects of intestinal flora and health also occur here. For most probiotics, such as Lactobacillus and especially Bifidobacteria, several factors may restrict their use, including susceptibility to oxygen, gastric juice, and bile salt. Therefore, protective measures must be taken, of which microencapsulation has shown great promise (Pedroso et al., 2013; Rosas-Flores et al., 2013; Solanki et al., 2013; Rodklongtan et al., 2014; Li et al., 2016). In this study, $8.62 \log \mathrm{cfu} / \mathrm{g} \mathrm{B}$. breve survived after SGF, SBF, and SIF treatments, which is sufficient to enable health-promoting effects.

\section{Storage Stability}

As shown in Figure 3, the number of viable cells in the beads decreased by $0.94,1.42$, and $3.29 \mathrm{log} \mathrm{cfu} / \mathrm{g}$ after storage for $13 \mathrm{wk}$ at -20 and $4^{\circ} \mathrm{C}$ and ambient temperature $\left(20 \pm 2^{\circ} \mathrm{C}\right)$, respectively. Meanwhile, the unencapsulated cells decreased by $1.46,2.10$, and 4.11 $\log \mathrm{cfu} / \mathrm{g}$, respectively at -20 and $4^{\circ} \mathrm{C}$ and ambient temperature $\left(20 \pm 2^{\circ} \mathrm{C}\right)$ for $13 \mathrm{wk}$. The results showed that encapsulation of probiotics could significantly increase the survival rate of the cells, and the storage effect of the probiotics was the best at $-20^{\circ} \mathrm{C}$. Under different temperatures, a high number of cells were alive in beads than among those unencapsulated cells $(P<0.05)$.

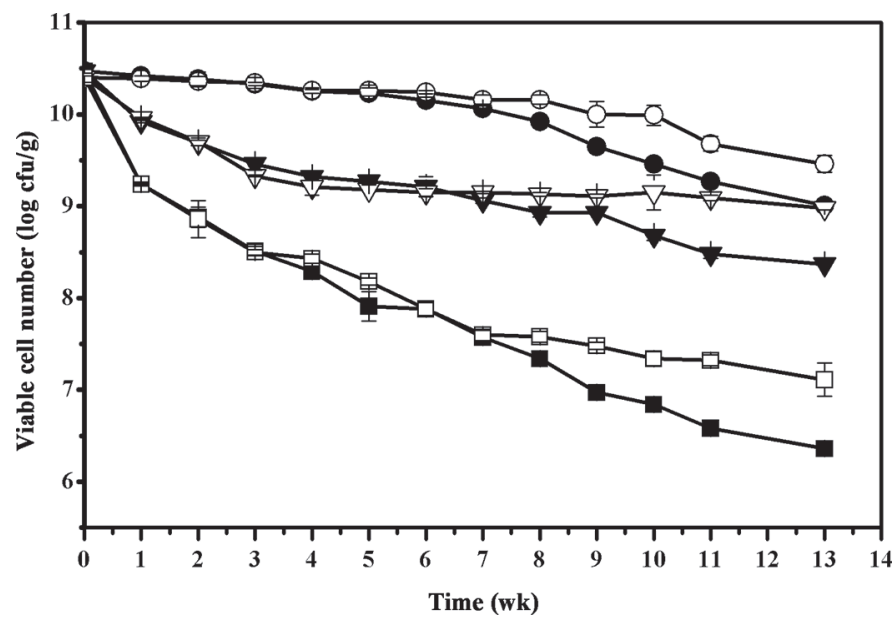

Figure 3. Storage stability of Bifidobacterium breve beads $(\bigcirc$ $-20^{\circ} \mathrm{C} ; \Delta 4^{\circ} \mathrm{C} ; \square$ ambient temperature) versus unencapsulated $B$. breve $\left(-20^{\circ} \mathrm{C} ; 4^{\circ} \mathrm{C} ; \boldsymbol{\square}\right.$ ambient temperature) over 3 mo of storage at different temperatures. The data are expressed as mean $\pm \mathrm{SD}$ (n $=6)$.
Table 1. Results of simulated gastrointestinal tract test $(\log \mathrm{cfu} / \mathrm{g})^{1}$

\begin{tabular}{lrr}
\hline & $\begin{array}{c}\text { Unencapsulated } \\
\text { Bifidobacterium } \\
\text { breve }\end{array}$ & \multicolumn{1}{c}{$\begin{array}{c}\text { B. breve } \\
\text { beads }\end{array}$} \\
\hline Group & $10.45 \pm 0.01$ & $10.38 \pm 0.02$ \\
Primary colonies & $6.17 \pm 0.07$ & $9.45 \pm 0.06$ \\
Colonies after SGF treatment & $5.74 \pm 0.03$ & $8.62 \pm 0.07$ \\
Colonies after SBF treatment & $5.63 \pm 0.07$ & $8.62 \pm 0.06$ \\
Colonies after SIF treatment &
\end{tabular}

${ }^{1}$ Three batches of beads were prepared independently, and the results are expressed as mean $\pm \mathrm{SD}$. $\mathrm{SBF}=$ simulated bile juice; $\mathrm{SGF}=$ simulated gastric fluid; SIF = simulated intestinal fluid.

\section{Yogurt Evaluation}

Viscosity. The viscosity of yogurt influences both the taste and stability of the product (Rivera and Matheus, 2009; Janiaski et al., 2016). Figure 4 shows the viscosity changes of each group during 7-d storage. At d 0, the EBAF group showed the lowest viscosity $(2,235.67 \mathrm{cP})$, while the viscosity of both the UBFF and EBFF groups was higher than that of the $\mathrm{BC}$ group, suggesting that $B$. breve was involved in the yogurt fermentation when added together with the commercial starter. The higher viscosity of the EBFF group could be attributable to the agglomeration effects of pectin with milk protein during fermentation. At the end of the experiment, the viscosity of the UBAF group was lowest, followed by that of the EBAF group. The slower increase of the yogurt viscosity in the EBAF group revealed the lower degree post fermentation.

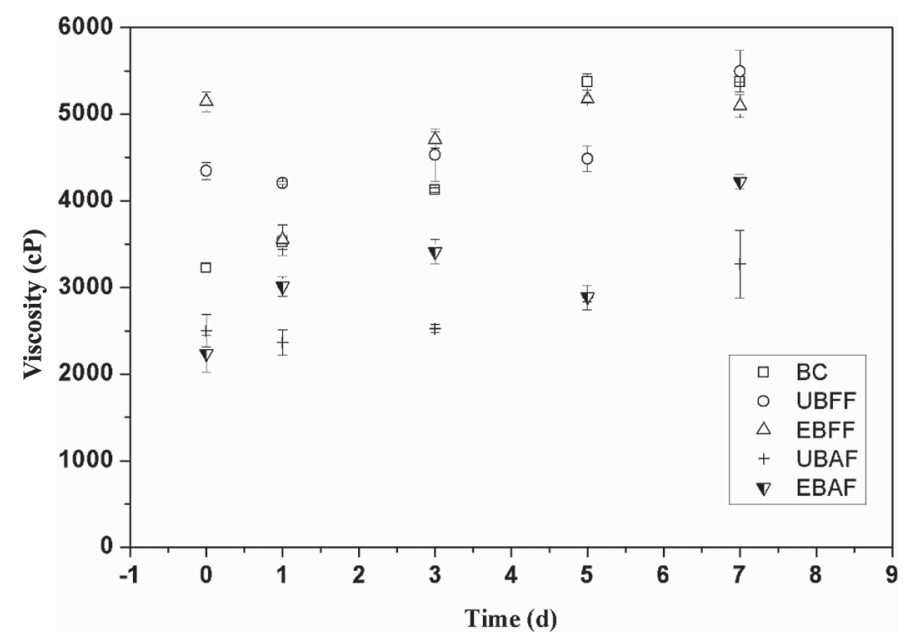

Figure 4. The yogurt viscosity of each group was measured in triplicate, and the values are expressed as mean $\pm \mathrm{SD} . \mathrm{BC}=$ milk fermented with commercial yogurt starter; UBFF = unencapsulated Bifidobacterium breve added to fresh milk and then fermented; EBFF $=$ encapsulated $B$. breve added to fresh milk and then fermented; $\mathrm{UBAF}=$ unencapsulated $B$. breve added after yogurt fermentation with commercial starter; EBAF $=$ encapsulated $B$. breve beads added after yogurt fermentation with commercial starter. 

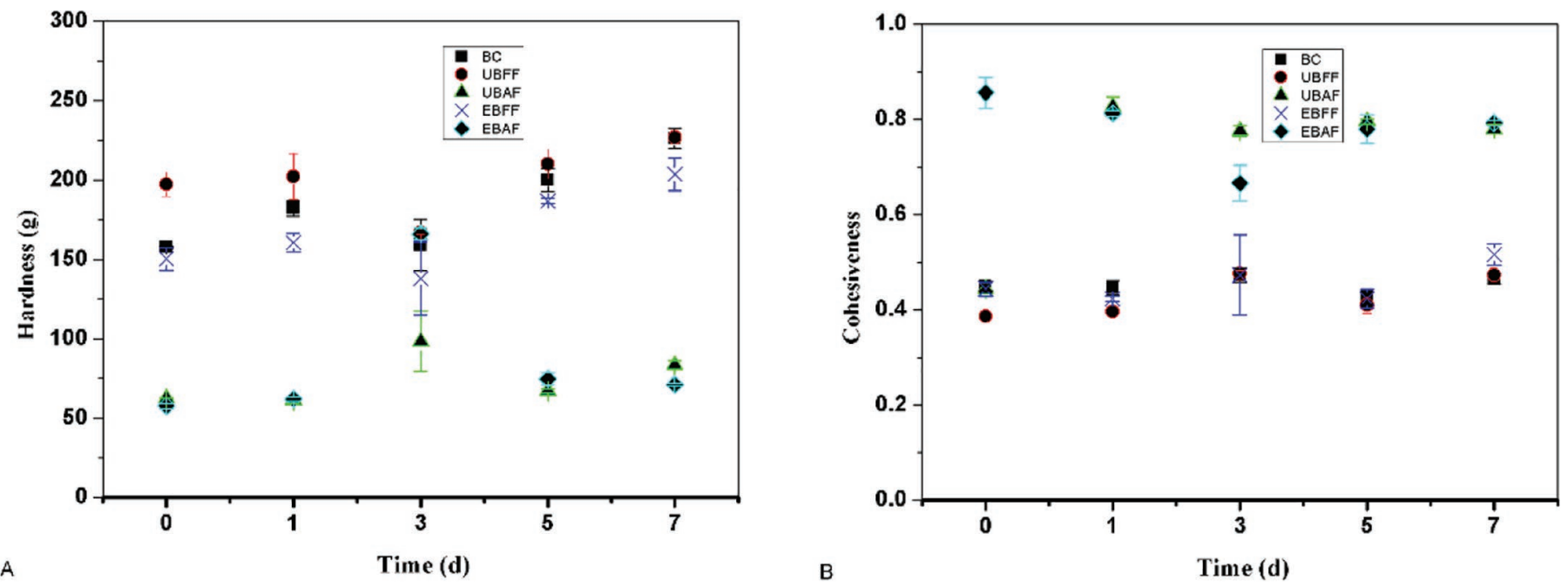

Figure 5. Hardness and cohesiveness of yogurts. $\mathrm{BC}=$ milk fermented with commercial yogurt starter; UBFF $=$ unencapsulated Bifidobacterium breve added to fresh milk and then fermented; $\mathrm{EBFF}=$ encapsulated $B$. breve added to fresh milk and then fermented; UBAF $=$ unencapsulated $B$. breve added after yogurt fermentation with commercial starter; EBAF = encapsulated $B$. breve beads added after yogurt fermentation with commercial starter. Yogurt samples from each group were measured in triplicate, and the values are expressed as mean \pm SD.

Hardness and cohesiveness are important in evaluating the yogurt texture (Mudgil et al., 2017), and they were determined by texture analysis for the different treatment groups after storage for $0,1,3,5$, and $7 \mathrm{~d}$ (Figure 5). Hardness is regarded as the force required to attain a certain deformation, and it serves as a measure of yogurt firmness (Mudgil et al., 2017). The hardness of the $\mathrm{BC}, \mathrm{UBFF}$, and EBFF groups were significantly higher than those of the UBAF and EBAF groups $(P<$ 0.01). The hardness of the UBAF and EBAF groups was most stable within $7 \mathrm{~d}$ (Figure 5A). Our results show that the trends of texture changes from $\mathrm{BC}, \mathrm{UBFF}$, and EBFF groups were similar, while the UBAF and EBAF groups showed similar trends. The values of the UBFF group were closest to those of the BC group. The texture index values of the UBAF group and the EBAF group were significantly different from those of the $\mathrm{BC}$ group. The unencapsulated bacteria and the $B$. breve beads added after fermentation had a significant effect on the texture of the yogurt, while the changes of the different indexes during the storage period were relatively stable within a certain range. Figure 5B shows that the cohesiveness values of the EBAF and UBAF groups were significantly higher than those of the other groups $(P<0.01)$. The cohesiveness of the EBAF group showed a downward trend in the first $3 \mathrm{~d}$ and gradually increased thereafter. The overall changes in other groups were not obvious. Yogurt cohesiveness is regarded as the level to which the tested yogurt can be deformed before it ruptures, and it thus serves as a measure of the strength of internal bonds. It is related to consumer acceptability of yogurt and is an impor- tant aspect of the yogurt texture (Mudgil et al., 2017). Therefore, both the EBAF and UBAF groups showed better eating quality compared with the other groups. The other 3 groups had no significant differences in cohesiveness.

$p H$. The $\mathrm{pH}$ value is an important indicator for evaluating the yogurt quality and represents the amount of free $\mathrm{H}^{+}$in the yogurt. As shown in Figure 6, during storage of yogurt for $7 \mathrm{~d}$ at $4^{\circ} \mathrm{C}$, the $\mathrm{pH}$ values of all groups remained steady.

Acidity. Yogurt $\mathrm{pH}$ determines the amount of ionized $\mathrm{H}^{+}$in the yogurt, while the acidity measures the total acidity of the yogurt, including the number of ionized $\mathrm{H}^{+}$and non-ionized $\mathrm{H}^{+}$. The degree of nonionized $\mathrm{H}^{+}$in the yogurt may cause the acidity and the $\mathrm{pH}$ measurement results to differ. As shown in Figure 7 , the acidity of the BC group did not change much during the 7-d storage and stayed the lowest among all groups, while the acidity of EBAF remained relatively higher but the difference was not significant. The acidity of yogurt may affect the yogurt viscosity because under acidic conditions, casein molecules form tiny subcolloidal molecular groups. When the acidity of yogurt reaches a certain value, the subcolloidal molecules are connected as colloidal molecules by the action of calcium phosphate, and the colloidal molecules aggregate again to form a homogeneous network of hydrated proteins, reaching a peak viscosity.

Bifidobacterium breve Viability. The B. breve viability was determined after the bacteria were subjected to the simulated GI test. At d 0, the survival rate of the $B$. breve was $32.17,35.85,35.01,76.37$, and $77.63 \%$ 


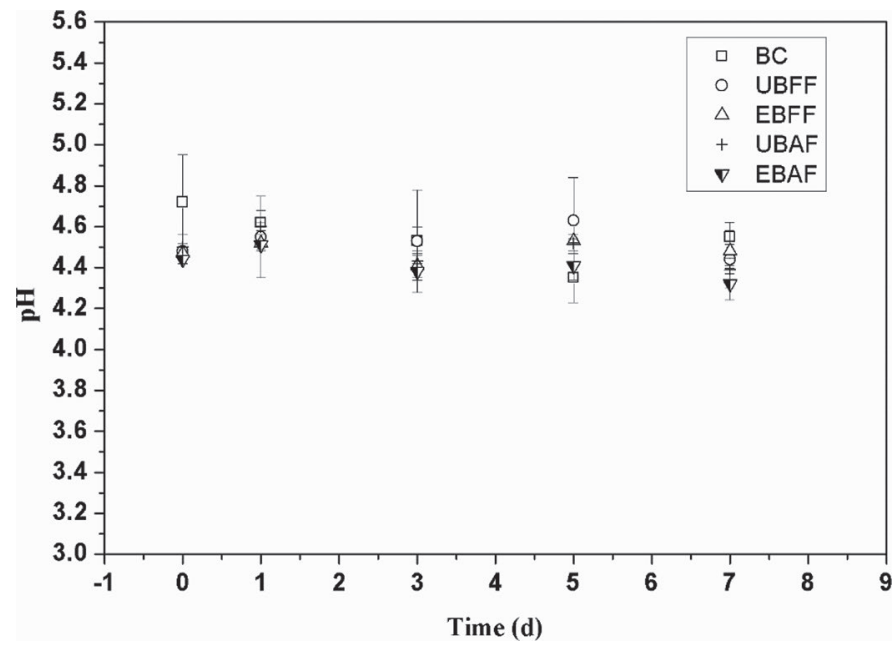

Figure 6. $\mathrm{pH}$ values of yogurt. $\mathrm{BC}=$ milk fermented with commercial yogurt starter; UBFF $=$ unencapsulated Bifidobacterium breve added to fresh milk and then fermented; $\mathrm{EBFF}=$ encapsulated $B$. breve added to fresh milk and then fermented; UBAF $=$ unencapsulated $B$. breve added after yogurt fermentation with commercial starter; $\mathrm{EBAF}=$ encapsulated $B$. breve beads added after yogurt fermentation with commercial starter. Yogurt samples from each group were measured in triplicate, and the values are expressed as mean $\pm \mathrm{SD}$.

for BC, UBFF, UBAF, EBFF, and EBAF groups, respectively. After storage for $1 \mathrm{~d}$, the survival rates of B. breve were $33.96,39.34,37.28,79.94$, and $78.07 \%$ for $\mathrm{BC}$, UBFF, UBAF, EBFF, and EBAF groups,

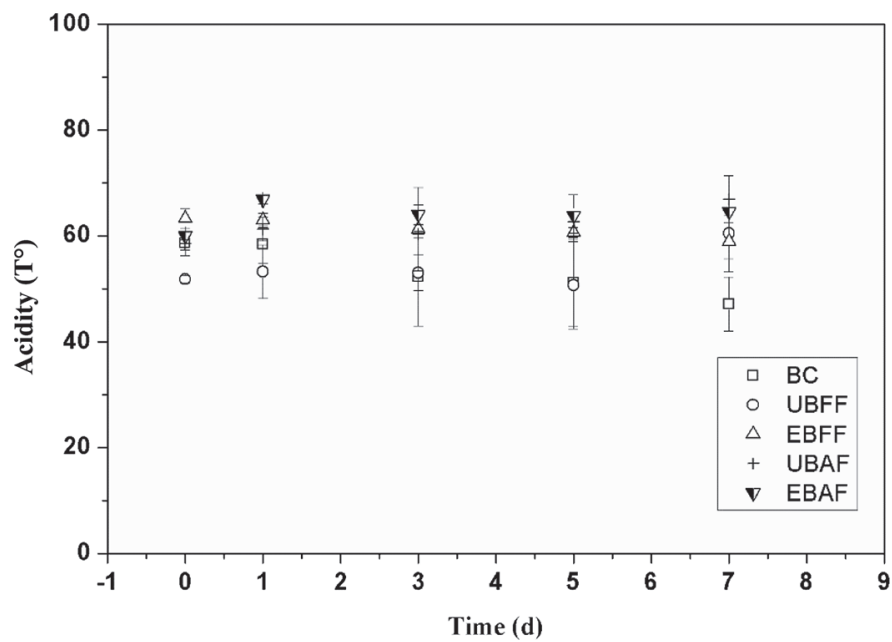

Figure 7. Determination of yogurt acidity (degrees Theurer, ${ }^{\circ} \mathrm{T}$ ). $\mathrm{BC}=$ milk fermented with commercial yogurt starter; $\mathrm{UBFF}=$ unencapsulated Bifidobacterium breve added to fresh milk and then fermented; EBFF = encapsulated B. breve added to fresh milk and then fermented; UBAF = unencapsulated $B$. breve added after yogurt fermentation with commercial starter; EBAF = encapsulated $B$. breve beads added after yogurt fermentation with commercial starter. Yogurt samples from each group were measured in triplicate, and the values are expressed as mean $\pm \mathrm{SD}$. respectively (Table 2). At the end of the $\mathrm{d} 7$, the $B$. breve survival rates were $29.72,32.03,32.39,67.04$, and $74.75 \%$ for BC, UBFF, UBAF, EBFF, and EBAF groups, respectively. The encapsulation of $B$. breve into LMP beads protected the cells from damage during storage and during passage through the simulated GI tract. The microencapsulation process increased the $B$. breve number, which was in agreement with other studies (Adhikari et al., 2000; Allgeyer et al., 2010; Jones et al., 2012).

Figure 8 shows the images of different yogurt product. The products did not differ in appearance and seemed to be homogeneous (see also Supplemental Video; https://doi.org/10.3168/jds.2018-15597). The homogeneous appearance of the products suggests that the LMP beads are compatible with yogurt.

Discrimination of Different Yogurt by Electronic Nose and Electronic Tongue. Linear discriminant analysis (LDA) is a statistical method for discriminating the sample type, in which the new components or items of unknown category are discriminated and classified into known categories by establishing a certain function (a linear combination of independent variables versus a discriminant function) based on the nature of the things of the known category (independent variables). Linear discriminant analysis has the advantages of a good classification effect and ease of use, and consequently, it is one of the commonly used pattern recognition methods for electronic nose and electronic tongue analysis. Figure 9A shows the LDA component graph from discriminant function analysis by iNose evaluation, in which the discrimination index (DI) was $91.8 \%$. The clustering trend of samples from each group on the classification map is obvious, and the samples from each group were well separated, indicating that the discriminant function could effectively classify the yogurt samples from different fermentation treatments. The yogurt sample difference between the EBAF and the BC group was the smallest, indicating that the $B$. breve beads added during the late stages of yogurt fermentation had little effect on the flavor of the yogurt itself and did not substantially change its odor. Figure 10A is the LDA component graph from discriminant function analysis after SmarTongue evaluation, in which the DI reaches $95.1 \%$. The clustering trend of samples from each group on the classification map is obvious, and the distance among samples from each group is relatively great, indicating that the discriminant function can effectively classify the yogurt samples that underwent different fermentation conditions.

The purpose of PCA in electronic nose or electronic tongue detection is to use a few new variables instead of the original variables to represent the original informa- 
Table 2. Results of simulated gastrointestinal release test $(\log \mathrm{cfu} / \mathrm{g})^{1}$

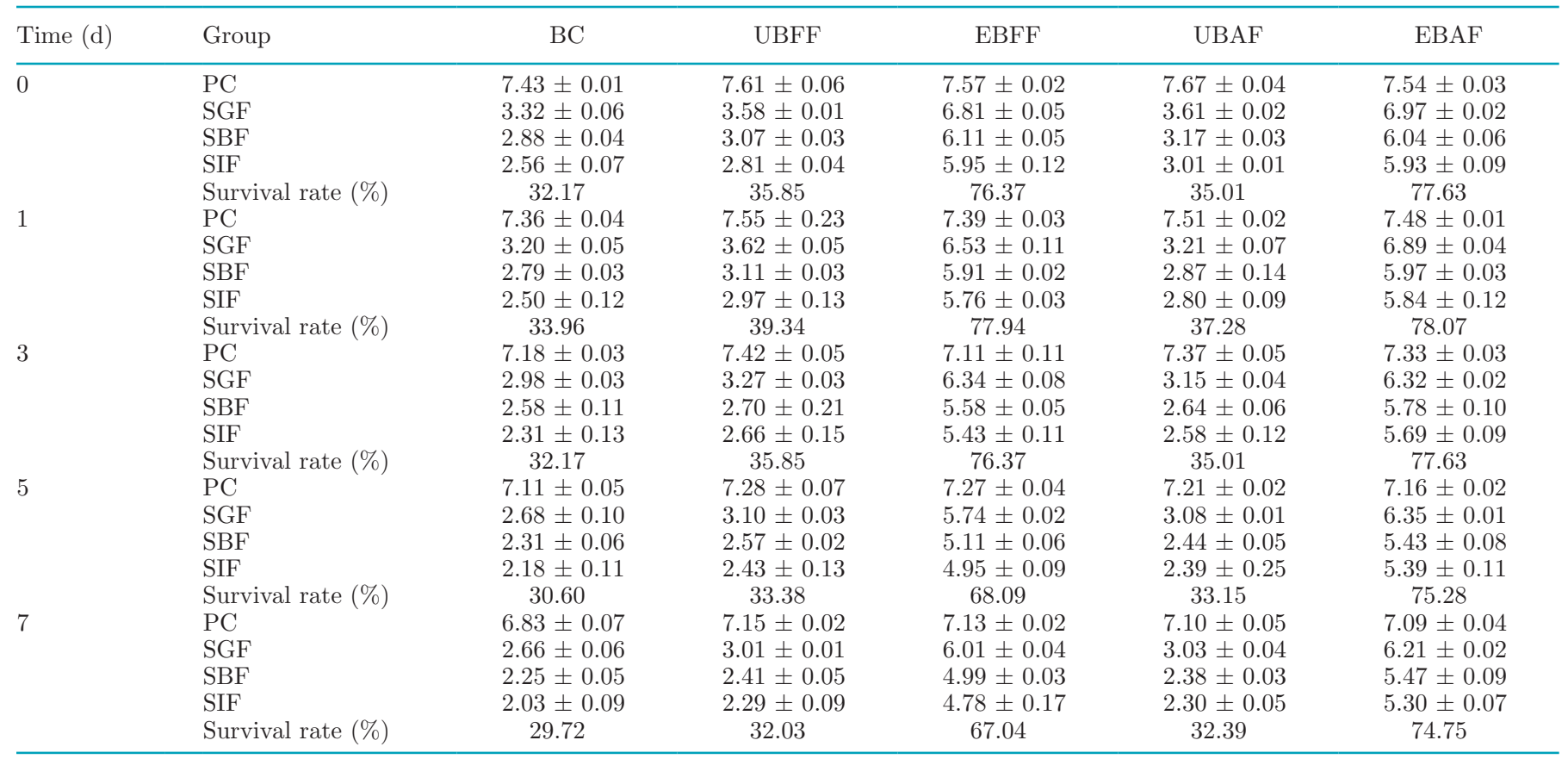

${ }^{1}$ The yogurt samples from different groups were taken at different times after fermentation and then treated with simulated gastric fluid, bile, or intestinal juice in turn. After this treatment, the number of Bifidobacterium breve was enumerated. BC = milk fermented with commercial yogurt starter; UBFF = unencapsulated $B$. breve added to fresh milk and then fermented; EBFF = encapsulated $B$. breve added to fresh milk and then fermented; UBAF = unencapsulated B. breve added after yogurt fermentation with commercial starter; EBAF = encapsulated $B$. breve beads added after yogurt fermentation with commercial starter; PC = primary colonies; $\mathrm{SGF}=$ simulated gastric fluid; $\mathrm{SBF}=$ simulated bile fluid; SIF = simulated intestinal fluid.

tion as much as possible after the dimensionality reduction processing (Ciosek et al., 2005). The scatter plots for the main component were obtained after the PCA of the original data obtained by iNose evaluation, in which each point represents 1 sample, and the distance between points represents the characteristic difference among different detection points (Figure 9B). PC1 and $\mathrm{PC} 2$ have variance contribution rates of 98.0 and $1.0 \%$, respectively, with a cumulative contribution rate of $99.0 \%$, which can reflect a large amount of information of the sample as a whole. The PCA DI value is $91.8 \%$, indicating an excellent discriminant result, and yogurt samples from the different groups can be distinguished well. The yogurt samples in BC, UBFF, and EBFF groups were clustered in different regions of the PCA diagram, indicating that the electronic nose could distinguish these yogurt samples. The partial overlap of the EBAF and UBAF groups reflected the similarity of the yogurt volatilization from these 2 groups. The distance between the $\mathrm{BC}$ and $\mathrm{EBFF}$ groups was the largest in the PCA chart, indicating significant different volatile components between them. Meanwhile, the distance between the $\mathrm{BC}$ and $\mathrm{EBAF}$ group in the PCA chart was the smallest, indicating that the flavor differ- ence between the BC and EBAF groups was not significant. Flavor difference also existed between the yogurt samples from the UBFF and UBAF groups, suggesting that the unencapsulated $B$. breve contributed to the flavor to yogurt and the encapsulating process caused the $B$. breve to be unavailable for fermentation process.

The PCA score plot for the electronic tongue analysis after pretreatment of the yogurt samples is shown in Figure 10B. PC1 and PC2 have variance contribution rates of $37.5 \%$ and $26.2 \%$, respectively, with a cumulative contribution rate of $63.7 \%$, which represents the major information of the samples as a whole. The PCA DI value is $95.1 \%$, indicating an excellent discriminant result; yogurt samples from the different groups could be distinguished well. Clustering in different regions of the PCA diagram indicated that the electronic tongue could distinguish among these yogurt samples. The distance between the BC and EBFF groups was shortest in the PCA chart, with the longest distance found between the BC and UBAF groups. The distance between the $\mathrm{BC}$ and EBAF yogurts was shorter than that between the BC and UBAF yogurts. These results indicated that the $B$. breve was fully isolated from fermentation process when encapsulated. 

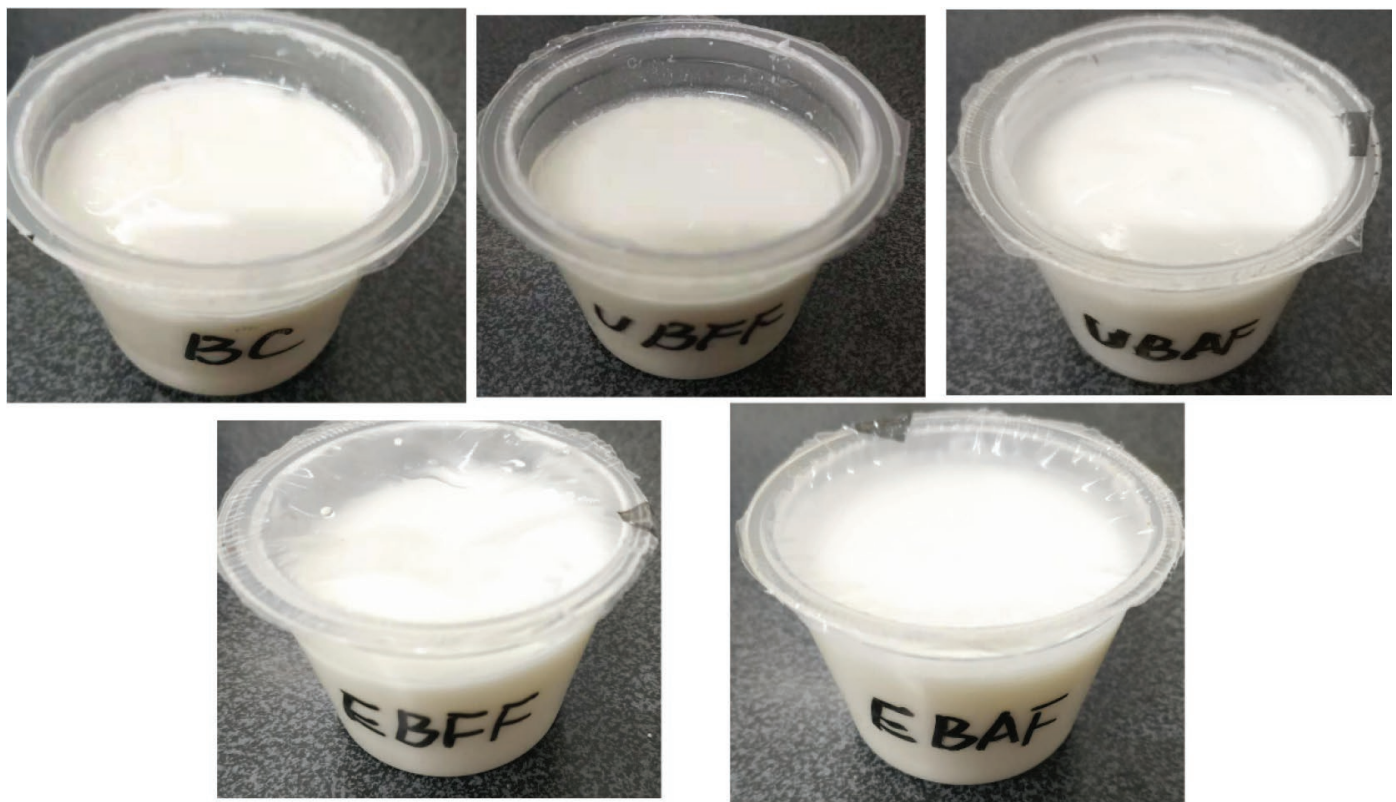

Figure 8. Images of yogurt products. $\mathrm{BC}=$ milk fermented with commercial yogurt starter; UBFF $=$ unencapsulated Bifidobacterium breve added to fresh milk and then fermented; EBFF $=$ encapsulated $B$. breve added to fresh milk and then fermented; UBAF $=$ unencapsulated $B$. breve added after yogurt fermentation with commercial starter; EBAF = encapsulated $B$. breve beads added after yogurt fermentation with commercial starter.

\section{CONCLUSIONS}

In this study, we prepared $B$. breve beads using LMP as the encapsulating material. The beads were white and the particle size distribution was uniform and spherical, with encapsulation efficiency higher than
99\%. The number of viable $B$. breve in LMP beads decreased by $1.76 \log \mathrm{cfu} / \mathrm{g}$ after simulated GI tests, while unencapsulated $B$. breve decreased by $4.82 \mathrm{log}$ $\mathrm{cfu} / \mathrm{g}$ after the same treatment. The results of the storage stability test showed that microencapsulation could significantly improve the viability of the encapsulated
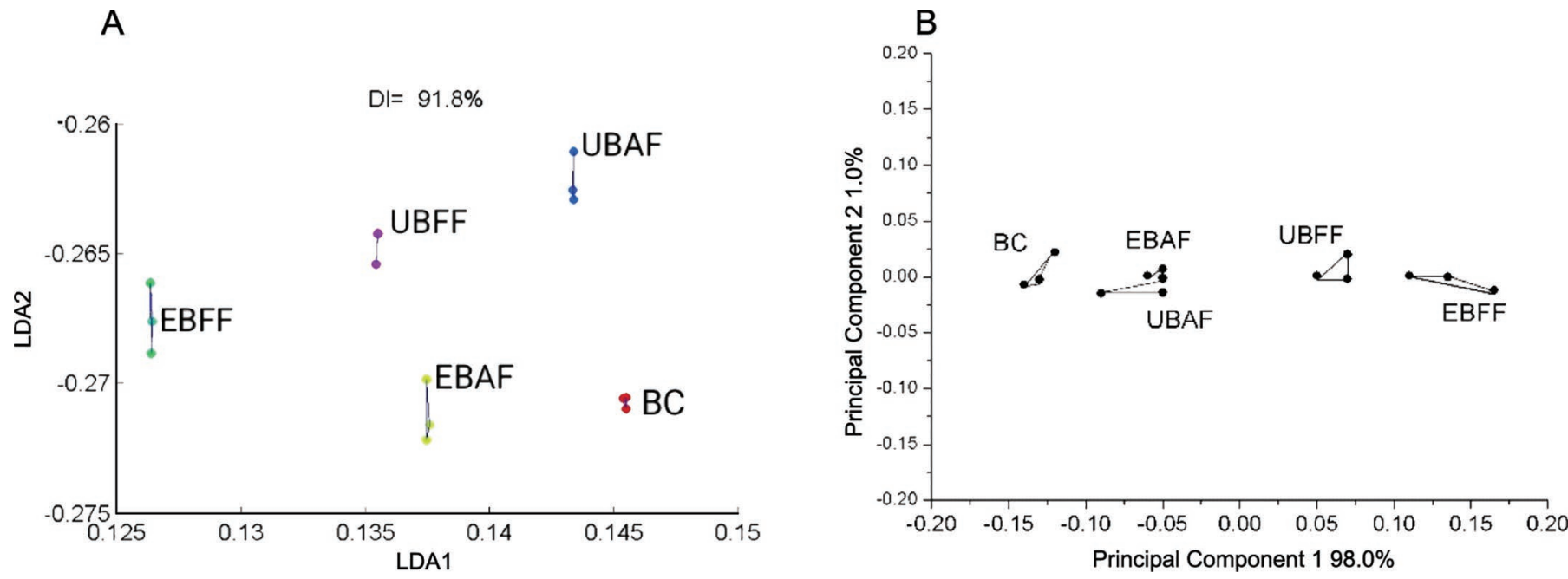

Figure 9. iNose (iNose system, Isenso, New York, NY) evaluation of the different yogurt samples with (A) linear discriminant analysis (LDA) and $(\mathrm{B})$ principal component analysis. $\mathrm{BC}=$ milk fermented with commercial yogurt starter; UBFF = unencapsulated Bifidobacterium breve added to fresh milk and then fermented; $\mathrm{EBFF}=$ encapsulated $B$. breve added to fresh milk and then fermented; UBAF $=$ unencapsulated $B$. breve added after yogurt fermentation with commercial starter; EBAF = encapsulated $B$. breve beads added after yogurt fermentation with commercial starter. DI = discrimination index. 

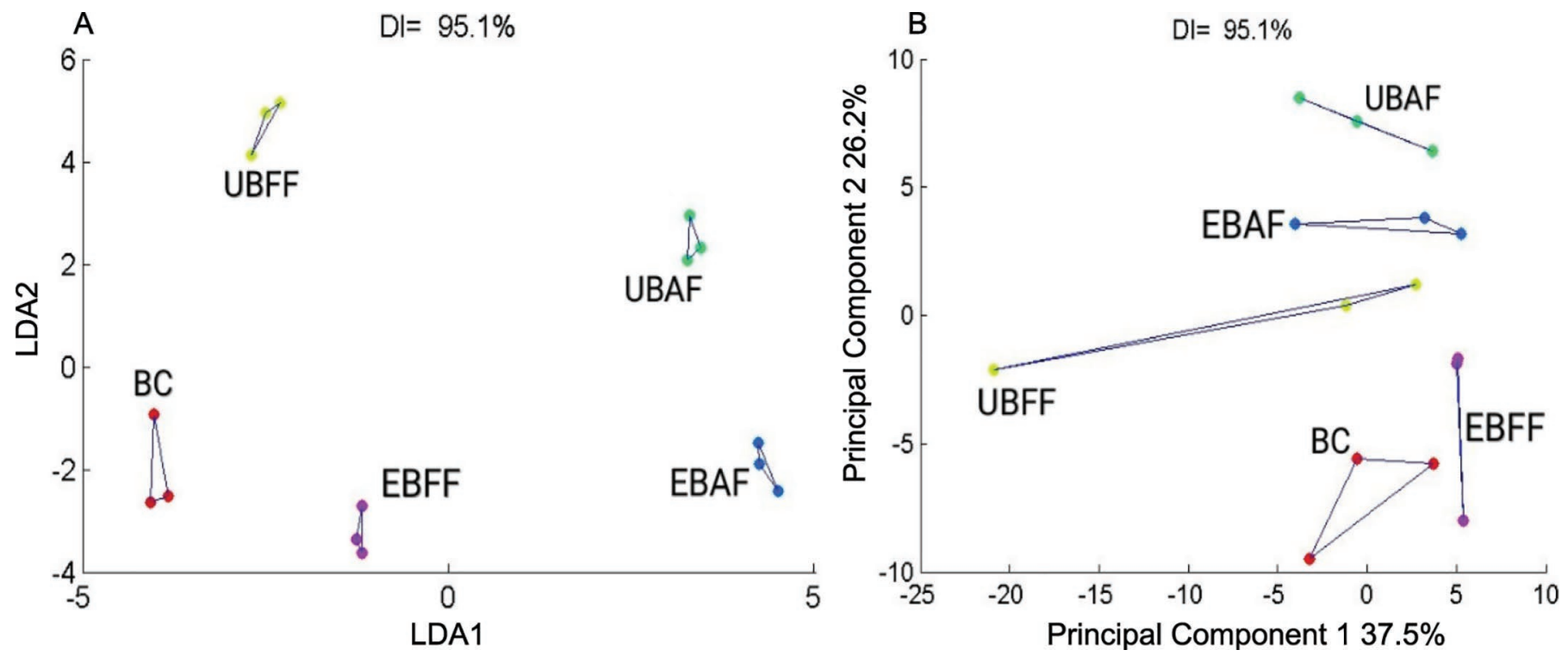

Figure 10. SmarTongue (SmarTongue system, Isenso, New York, NY) evaluation of the different yogurt samples with (A) linear discriminant analysis (LDA) and (B) principal component analysis. $\mathrm{BC}=$ milk fermented with commercial yogurt starter; UBFF $=$ unencapsulated Bifidobacterium breve added to fresh milk and then fermented; EBFF = encapsulated B. breve added to fresh milk and then fermented; UBAF $=$ unencapsulated $B$. breve added after yogurt fermentation with commercial starter; EBAF = encapsulated B. breve beads added after yogurt fermentation with commercial starter. DI = discrimination index.

cells, and the storage effect was best at $-20^{\circ} \mathrm{C}$. The encapsulation of $B$. breve into LMP also increased the stability of the $B$. breve in yogurt during storage at $4^{\circ} \mathrm{C}$. The difference in yogurt samples between the EBAF and $\mathrm{BC}$ groups was the smallest, indicating that $B$. breve beads added during the middle and late stages of yogurt fermentation had little effect on the flavor of yogurt itself and did not cause large differences in yogurt odor. In conclusion, LMP appears to be ideal for encapsulating $B$. breve and shows potential use in yogurt fermentation.

\section{ACKNOWLEDGMENTS}

This work was supported by the Natural Science Foundation of Heilongjiang Province (C2016049, Heilongjiang, China), the National Natural Science Foundation (No. 31871747, Beijing, China), Harbin city technology bureau youth talented person project (RC2017QN020010, Harbin, China), and support program from Biomass and Mineral Resources Efficient Use Collaborative Innovation Center R\&D incubation and transformation (Harbin, China).

\section{REFERENCES}

Adhikari, K., A. Mustapha, I. U. Grun, and L. Fernando. 2000. Viability of microencapsulated bifidobacteria in set yogurt during refrigerated storage. J. Dairy Sci. 83:1946-1951.
Allgeyer, L. C., M. J. Miller, and S. Y. Lee. 2010. Drivers of liking for yogurt drinks with prebiotics and probiotics. J. Food Sci. 75:S212-S219

Aryana, K. J., and D. W. Olson. 2017. A 100-year review: Yogurt and other cultured dairy products. J. Dairy Sci. 100:9987-10013.

Aydin, Z., and J. Akbuga. 1996. Preparation and evaluation of pectin beads. Int. J. Pharm. 137:133-136.

Belščak-Cvitanović, A., D. Komes, S. Karlović, S. Djaković, I. Spoljarić, G. Mršić, and D. Ježek. 2015. Improving the controlled delivery formulations of caffeine in alginate hydrogel beads combined with pectin, carrageenan, chitosan and psyllium. Food Chem. 167:378-386.

Bigucci, F., B. Luppi, T. Cerchiara, M. Sorrenti, G. Bettinetti, L. Rodriguez, and V. Zecchi. 2008. Chitosan/pectin polyelectrolyte complexes: selection of suitable preparative conditions for colonspecific delivery of vancomycin. Eur. J. Pharm. Sci. 35:435-441.

Bourgeois, S., M. Gernet, D. Pradeau, A. Andremont, and E. Fattal. 2006. Evaluation of critical formulation parameters influencing the bioactivity of beta-lactamases entrapped in pectin beads. Int. J. Pharm. 324:2-9.

Caleja, C., L. Barros, A. L. Antonio, M. Carocho, M. B. P. P. Oliveira, and I. C. F. R. Ferreira. 2016. Fortification of yogurts with different antioxidant preservatives: A comparative study between natural and synthetic additives. Food Chem. 210:262-268.

Champagne, C. P. 2012. Microencapsulation of probiotics in food Challenges and future prospects. Ther. Deliv. 3:1249-1251.

Champagne, C. P., A. Gomes da Cruz, and M. Daga. 2018. Strategies to improve the functionality of probiotics in supplements and foods. Curr. Opin. Food Sci. 22:160-166.

Chávarri, M., I. Marañón, R. Ares, F. C. Ibáñez, F. Marzo, and C. Villarán Mdel. 2010. Microencapsulation of a probiotic and prebiotic in alginate-chitosan capsules improves survival in simulated gastro-intestinal conditions. Int. J. Food Microbiol. 142:185-189.

Ciosek, P. Z. Brzozka, W. Wroblewski, E. Martinelli, C. Di Natale, and A. D'Amico. 2005. Direct and two-stage data analysis procedures based on PCA, PLS-DA and ANN for ISE-based electronic tongue-Effect of supervised feature extraction. Talanta $67: 590-596$ 
Cook, M. T., G. Tzortzis, D. Charalampopoulos, and V. V. Khutoryanskiy. 2012b. Microencapsulation of probiotics for gastrointestinal delivery. J. Control. Release 162:56-67.

Curti, C. A., P. M. Vidal, R. N. Curti, and A. N. Ramon. 2017. Chemical characterization, texture and consumer acceptability of yogurts supplemented with quinoa flour. Food Sci. Technol. 37:627-631.

Das, S., A. Chaudhury, and K. Y. Ng. 2011. Preparation and evaluation of zinc-pectin-chitosan composite particles for drug delivery to the colon: Role of chitosan in modifying in vitro and in vivo drug release. Int. J. Pharm. 406:11-20.

de Souza, J. R. R., J. I. X. de Carvalho, M. T. S. Trevisan, R. C. M. de Paula, N. M. P. S. Ricardo, and J. P. A. Feitosa. 2009. Chitosancoated pectin beads: Characterization and in vitro release of mangiferin. Food Hydrocoll. 23:2278-2286.

Ghibaudo, F., E. Gerbino, A. A. Hugo, M. G. Simões, P. Alves, B. F. O. Costa, V. Campo Dall' Orto, A. Gómez-Zavaglia, and P. N. Simões. 2018. Development and characterization of iron-pectin beads as a novel system for iron delivery to intestinal cells. Colloids Surf. B Biointerfaces 170:538-543.

Hill, C., F. Guarner, G. Reid, G. R. Gibson, D. J. Merenstein, B. Pot, L. Morelli, R. B. Canani, H. J. Flint, S. Salminen, P. C. Calder, and M. E. Sanders. 2014. Expert consensus document. The International Scientific Association for Probiotics and Prebiotics consensus statement on the scope and appropriate use of the term probiotic. Nat. Rev. Gastroenterol. Hepatol. 11:506-514.

Janiaski, D. R., T. C. Pimentel, A. G. Cruz, and S. H. Prudencio. 2016. Strawberry-flavored yogurts and whey beverages: What is the sensory profile of the ideal product? J. Dairy Sci. 99:5273-5283.

Jones, M. L., C. J. Martoni, S. Tamber, M. Parent, and S. Prakash. 2012. Evaluation of safety and tolerance of microencapsulated Lactobacillus reuteri NCIMB 30242 in a yogurt formulation: A randomized, placebo-controlled, double-blind study. Food Chem. Toxicol. 50:2216-2223.

Jung, J., R. D. Arnold, and L. Wicker. 2013. Pectin and charge modified pectin hydrogel beads as a colon-targeted drug delivery carrier. Colloids Surf. B Biointerfaces 104:116-121.

Khosravi Zanjani, M. A., B. Ghiassi Tarzi, A. Sharifan, and N. Mohammadi. 2014. Microencapsulation of probiotics by calcium alginate-gelatinized starch with chitosan coating and evaluation of survival in simulated human gastro-intestinal condition. Iran J. Pharm. Res. 13:843-852.

Li, C., C. L. Wang, Y. Sun, A. L. Li, F. Liu, and X. C. Meng. 2016. Microencapsulation of Lactobacillus rhamnosus GG by transglutaminase cross-linked soy protein isolate to improve survival in simulated gastrointestinal conditions and yoghurt. J. Food Sci. 81:M1726-M1734.

Liu, L., M. L. Fishman, K. B. Hicks, M. Kende, and G. Ruthel. 2006. Pectin/zein beads for potential colon-specific drug delivery: Synthesis and in vitro evaluation. Drug Deliv. 13:417-423.

Mudgil, D., S. Barak, and B. S. Khatkar. 2017. Texture profile analysis of yogurt as influenced by partially hydrolyzed guar gum and process variables. J. Food Sci. Technol. 54:3810-3817.

Nguyen, A. T., P. Winckler, P. Loison, Y. Wache, and O. Chambin. 2014. Physico-chemical state influences in vitro release profile of curcumin from pectin beads. Colloids Surf. B Biointerfaces 121:290-298.

Oehme, A., A. Valotis, G. Krammer, I. Zimmermann, and P. Schreier. 2011. Preparation and characterization of shellac-coated anthocyanin pectin beads as dietary colonic delivery system. Mol. Nutr. Food Res. 55(Suppl 1):S75-S85.

Pedroso, D. L., M. Dogenski, M. Thomazini, R. J. Heinemann, and C. S. Favaro-Trindade. 2013. Microencapsulation of Bifidobacterium animalis subsp. lactis and Lactobacillus acidophilus in cocoa butter using spray chilling technology. Braz. J. Microbiol. 44:777-783.

Pu, F., Y. Guo, M. Li, H. Zhu, S. J. Wang, X. Shen, M. He, C. Y. Huang, and F. He. 2017. Yogurt supplemented with probiotics can protect the healthy elderly from respiratory infections: A randomized controlled open-label trial. Clin. Interv. Aging 12:1223-1231.

Ranadheera, C. S., C. A. Evans, M. C. Adams, and S. K. Baines. 2012. In vitro analysis of gastrointestinal tolerance and intestinal cell adhesion of probiotics in goat's milk ice cream and yogurt. Food Res. Int. 49:619-625.

Ranadheera, R. D. C. S., S. K. Baines, and M. C. Adams. 2010. Importance of food in probiotic efficacy. Food Res. Int. 43:1-7.

Ribeiro, L. N., A. C. Alcantara, M. Darder, P. Aranda, F. M. AraujoMoreira, and E. Ruiz-Hitzky. 2014. Pectin-coated chitosan-LDH bionanocomposite beads as potential systems for colon-targeted drug delivery. Int. J. Pharm. 463:1-9.

Rivera, J. A. R., and A. O. R. Matheus. 2009. Yogurt making by using probiotics (Bifidobacterium spp. and Lactobacillus acidophilus) and inulin. Rev. Fac. Agron. 26:223-242.

Rodklongtan, A., O. La-ongkham, S. Nitisinprasert, and P. Chitprasert. 2014. Enhancement of Lactobacillus reuteri KUB-AC5 survival in broiler gastrointestinal tract by microencapsulation with alginate-chitosan semi-interpenetrating polymer networks. J. Appl. Microbiol. 117:227-238.

Rosas-Flores, W., E. G. Ramos-Ramirez, and J. A. Salazar-Montoya. 2013. Microencapsulation of Lactobacillus helveticus and Lactobacillus delbrueckii using alginate and gellan gum. Carbohydr. Polym. 98:1011-1017.

Saldanha, L. G. 2008. US Food and Drug Administration regulations governing label claims for food products, including probiotics. Clin. Infect. Dis. 46(Suppl. 2):S119-S121, discussion S144-S151. PubMed

Sandolo, C., S. Pechine, A. Le Monnier, S. Hoys, C. Janoir, T. Coviello, F. Alhaique, A. Collignon, E. Fattal, and N. Tsapis. 2011. Encapsulation of Cwp84 into pectin beads for oral vaccination against Clostridium difficile. Eur. J. Pharm. Biopharm. 79:566-573.

Sandoval-Castilla, O., C. Lobato-Calleros, H. S. García-Galindo, J. Alvarez-Ramírez, and E. J. Vernon-Carter. 2010. Textural properties of alginate-pectin beads and survivability of entrapped $L b$. casei in simulated gastrointestinal conditions and in yoghurt. Food Res. Int. 43:111-117.

Sarao, L. K., and M. Arora. 2017. Probiotics, prebiotics, and microencapsulation: A review. Crit. Rev. Food Sci. Nutr. 57:344-371.

Solanki, H. K., D. D. Pawar, D. A. Shah, V. D. Prajapati, G. K. Jani, A. M. Mulla, and P. M. Thakar. 2013. Development of microencapsulation delivery system for long-term preservation of probiotics as biotherapeutics agent. BioMed Res. Int. 2013:620719.

Tomaro-Duchesneau, C., S. Saha, M. Malhotra, M. Coussa-Charley, I. Kahouli, M. L. Jones, A. Labbe, and S. Prakash. 2012. Probiotic ferulic acid esterase active Lactobacillus fermentum NCIMB 5221 APA microcapsules for oral delivery: Preparation and in vitro characterization. Pharmaceuticals (Basel) 5:236-248.

Vaziri, A. S., I. Alemzadeh, M. Vossoughi, and A. C. Khorasani. 2018. Co-microencapsulation of Lactobacillus plantarum and DHA fatty acid in alginate-pectin-gelatin biocomposites. Carbohydr. Polym. 199:266-275.

Vieira da Silva, B., J. C. M. Barreira, and M. B. P. P. Oliveira. 2016. Natural phytochemicals and probiotics as bioactive ingredients for functional foods: Extraction, biochemistry and protected-delivery technologies. Trends Food Sci. Technol. 50:144-158.

Vincent, R. R., and M. A. Williams. 2009. Microrheological investigations give insights into the microstructure and functionality of pectin gels. Carbohydr. Res. 344:1863-1871.

Yang, Y. J., and B. S. Sheu. 2012. Probiotics-containing yogurts suppress Helicobacter pylori load and modify immune response and intestinal microbiota in the Helicobacter pylori-infected children. Helicobacter 17:297-304.

Zhao, L. L., R. Feng, F. Z. Ren, and X. Y. Mao. 2018. Addition of buttermilk improves the flavor and volatile compound profiles of low-fat yogurt. Lebensm. Wiss. Technol. 98:9-17. 